\title{
Diaphragmatic ultrasound and pulmonary functions evaluation in thyroid patients: a case-control study
}

\author{
Heba H. Eltrawy ${ }^{1 *}$ (D), Inass Hassan Ahmad ${ }^{2}$, Fatma Mohamed Elhussieny ${ }^{3}$ and Sherief Abdullah Nassib ${ }^{4}$
}

\begin{abstract}
Background: Dyspnea is a frequent symptom among patients with thyroid disorders. However, its actual causative mechanism is not clear. The diaphragm is the main inspiratory muscle and contraction of the diaphragm is essential for breathing, so any disorder that interferes with contractile muscle function can cause diaphragm dysfunction which is associated with dyspnea. The objective of study is to assess the effect of thyroid disorders on diaphragm excursion and thickness.

Results: Diaphragmatic excursion during tidal, deep, and sniff respiration were significantly decreased in patients with thyroid disorder in comparison to control and significantly decreased in hypothyroid patients (right tidal 1.42 \pm 0.29 , right deep respiration $5.07 \pm 0.72$, and sniff $2.15 \pm 0.26 \mathrm{~cm}$ ) than hyperthyroid patients (right tidal $1.61 \pm$ 0.34 , right deep respiration $5.63 \pm 0.50$, and sniff $2.67 \pm 0.27 \mathrm{~cm}$ ) and than the control group (right tidal $2.17 \pm 0.27$, right deep respiration $6.63 \pm 0.33$, right sniff $2.89 \pm 0.19 \mathrm{~cm}$ ). Diaphragmatic thickness at end tidal inspiration was significantly decreased in patients with thyroid disorder in comparison to control ( $p$ value $<0.05$ ). There was negative correlation between diaphragmatic excursion and duration of disease.
\end{abstract}

Conclusion: Diaphragmatic excursion and thickness are affected in hypothyroidism compared to hyperthyroidism and control groups. There is significant negative correlation between diaphragmatic excursion and duration of disease in patients' group. Respiratory symptoms are more frequent in hypothyroid patients.

Keywords: Diaphragmatic excursion, Diaphragmatic thickness, Pulmonary function tests, Hypothyroidism, Hyperthyroidism

\section{Background}

Thyroid hormones play an important role in regulating the function of various systems of the human body including cardiovascular, respiratory, renal, homoeostasis, and vascular tone through their effect on metabolism [1].

Dyspnea is a frequent symptom among patients with thyroid disorders. However, the underlying pathophysiological mechanism remains unclear, except when the

\footnotetext{
* Correspondence: hebahamed182@gmail.com

'Department of Chest Diseases, Faculty of Medicine for Girls in Cairo,

Al-Azhar University, 11517 Al-Abbaseya, Cairo, Egypt

Full list of author information is available at the end of the article
}

patient has coexisting tracheal compression due to goiter or has cardiac failure [2].

The diaphragm is the master muscle for inspiration and represents two thirds of tidal volume. There is limitation in studies where diaphragmatic muscle strength, movement, and thickness have been assessed among patients with thyroid disorders. We reported results of our study in a case-control study of patients with uncontrolled hypothyroid and hyperthyroid disease demonstrating reduced diaphragm muscle strength in those patient categories by ultrasound.

Ultrasound evaluation of the diaphragm is simple, non-invasive, and widely used both in the clinical and research settings. The main variables that can be

\section{Springer Open}

(c) The Author(s). 2020 Open Access This article is licensed under a Creative Commons Attribution 4.0 International License, which permits use, sharing, adaptation, distribution and reproduction in any medium or format, as long as you give appropriate credit to the original author(s) and the source, provide a link to the Creative Commons licence, and indicate if changes were made. The images or other third party material in this article are included in the article's Creative Commons licence, unless indicated otherwise in a credit line to the material. If material is not included in the article's Creative Commons licence and your intended use is not permitted by statutory regulation or exceeds the permitted use, you will need to obtain permission directly from the copyright holder. To view a copy of this licence, visit http://creativecommons.org/licenses/by/4.0/. 
assessed using this technique include the static measurement of diaphragm thickness and the more dynamic evaluation of inspiratory diaphragm thickening fraction and excursion [3].

Thyroid disorders especially hypothyroidism have been known to affect the ear, nose, and throat region. The most common symptoms of rhinitis related to hypothyroidism are rhinorrhea and nasal obstruction due to an increase in sub mucosal connective tissue and hypertrophy of mucous glands [4].

\section{Methods}

This study was a case-control study which was conducted on one hundred and twenty subjects (aged 2560 years). They were classified into three groups, forty patients with hypothyroidism, forty patients with hyperthyroidism, and forty age- and sex-matched healthy volunteers as control group. Written informed consents were signed by all recruited participants. Patients with diabetes mellitus, hypertension, or organ failure; persons who cannot perform pulmonary function test; smokers; patients with any chest disease; and pregnant females were excluded (Figs. 1 and 2). All eligible patients were recruited from the endocrinology and internal medicine outpatient's clinics of Al-Zahraa University Hospital through the period from January 2019 to January 2020.

All subjects were subjected to careful medical history including upper and lower respiratory symptoms and clinical examination including anthropometric measurements.

\section{Biochemical analysis}

Measurement of serum thyroid stimulating hormone (TSH), free triiodothyronine (T3), and free thyroxine (T4) was done using Cobas e411 Hitachi Roche chemiluminescence technique. Normal ranges of TSH $(0.270-$

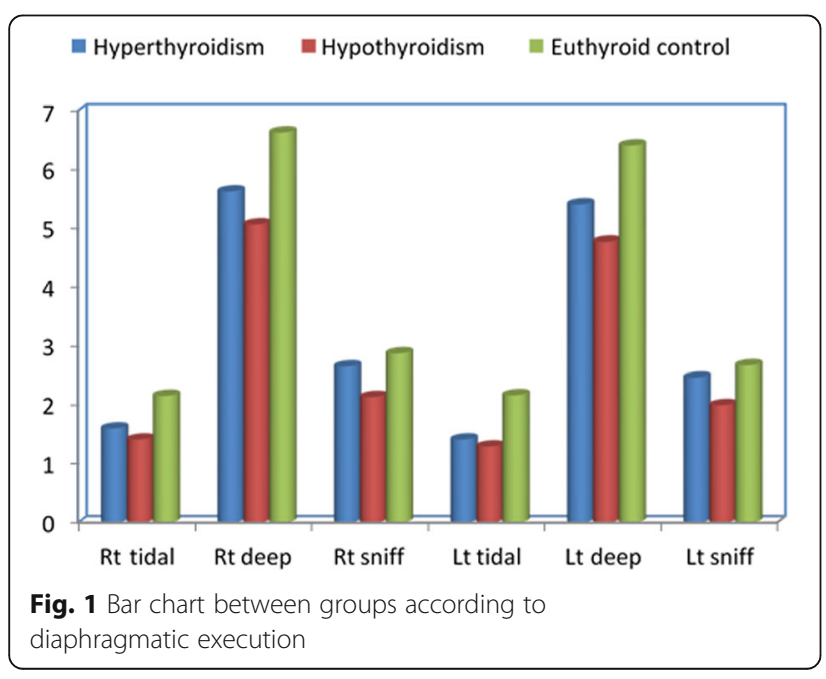

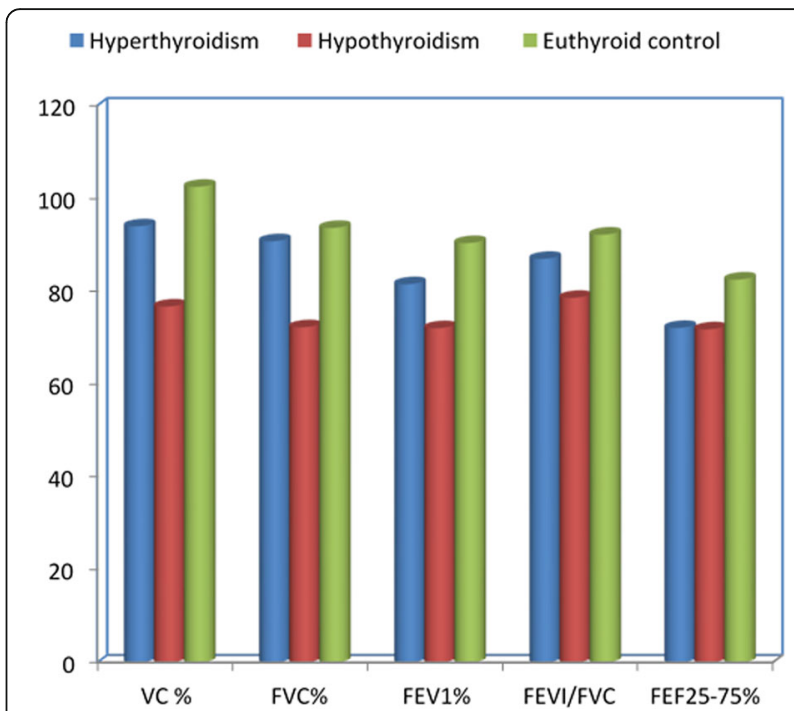

Fig. 2 Bar chart between groups according to pulmonary function test

$4.20 \mathrm{uIu} / \mathrm{mg})$, free T3 $(3.10-6.80 \mathrm{pmol} / \mathrm{l})$, and free $\mathrm{T} 4$ $(12.00-22.00 \mathrm{pmol} / \mathrm{l})$

\section{Spirometry}

Spirometry was carried out on MEDISOFT-HYPERAIR compact + flow meter pulmonary spirometer testingBelgium. Respiratory parameters measured included vital capacity (VC), forced vital capacity (FVC), forced expiratory volume in 1st second (FEV1), forced expiratory flow rate $25-75 \%$ predicted (FEF25-75\% predicted), and FEV1/FVC ratio. Spirometric indices were calculated using best out of 3 technically acceptable performances in accordance with the recommendations of the European Respiratory Society [5].

\section{Assessment of diaphragmatic excursions and diaphragm thickness}

Diaphragmatic excursions were measured in a supine position during tidal breathing and during deep and sniff breathing on the right and left sides by ultrasonography expressed in centimeters to cover the different physiological changes in lung volumes in relation to diaphragmatic activity. The machine used was ultrasound scanner (Sonoscape SSI6000, equipped with a $3.5 \mathrm{MHz}$ curvilinear and $8 \mathrm{MHz}$ linear probes, Nanshan, China). The diaphragmatic inspiratory excursion of each hemidiaphragm was measured in M-MODE [6]. A right ascending subcostal scan between the anterior axillary line and the midclavicular line was performed. Diaphragm was evaluated in B-MODE, and respiratory excursions were assessed in M-MODE. Examination consisted of 3 measurements of the inspiratory phase at rest and after deep inspiration and sniff [7]. Measurements in patients 
and healthy controls were evaluated by the same operator, freezing the image of the diaphragmatic curve during the respiratory cycle and measuring the distance from the base of the curve to the apex [8]. Diaphragm thickness was measured in millimeters in the zone of apposition of the diaphragm to the rib cage. A linear 10$\mathrm{MHz}$ probe was placed above the right 10th rib in the mid-axillary line. In this area, the diaphragm is observed as a three-layered structure: a non-echogenic central layer bordered by two echogenic layers (the peritoneum and the diaphragmatic pleurae) [9].

\section{Statistical analysis}

Recorded data were analyzed using the Statistical Package for Social Sciences, version 20.0 (SPSS Inc., Chicago, Illinois, USA). Quantitative data were expressed as mean \pm standard deviation (SD). Qualitative data were expressed as frequency and percentage. Independentsamples $t$-test of significance was used when comparing between two means. A one-way analysis of variance (ANOVA) was done when comparing between more than two means. Post hoc test, least significant difference (LSD) was used for multiple comparisons between different variables. Chi-square $\left(\chi^{2}\right)$ test of significance was used in order to compare proportions between qualitative parameters. Binary logistic regression was used to predict the outcome of categorical variable based on one or more predictor variables. The confidence interval was set to $95 \%$ and the margin of error accepted was set to $5 \%$. So, the probability $(P$ value $)<0.05$ was considered significant, $P$ value $<0.001$ was considered highly significant and $P$ value $>0.05$ was considered insignificant

\section{Results}

The results showed no statistically significant difference between hyperthyroidism, hypothyroidism and control groups as regards age (40.25 \pm 9.98 in hyperthyroidism, $40.70 \pm 8.87$ in hypothyroidism, and $42.30 \pm 8.95$ in controls), sex (30 female and 10 males in hyperthyroidism, 24 female and 16 male in hypothyroidism, and 28 female and 12 male in controls) with female predominance in all groups, and body mass index (25.68 \pm 2.55 in hyperthyroidism, $27.53 \pm 2.34$ in hypothyroidism, and 26.04 \pm 3.40 in controls) (Table 1).

This study revealed the presence of otolaryngeal and respiratory symptoms among patients' groups as hoarseness of voice presents in $35 \%$ of hyperthyroid patients versus $60 \%$ of hypothyroid patients, rhinitis $0 \%$ versus $5 \%$, dysphagia $18 \%$ versus $20 \%$, cough $8 \%$ versus $12 \%$, dyspnea $22 \%$ versus $22 \%$, and wheezes $0 \%$ versus $12 \%$, respectively, with significant difference. There was no statistically significant difference between hyperthyroid and hypothyroid patients as regards duration of the disease $(16.50 \pm 10.56$ months versus $21.30 \pm 10.15$ months), respectively (Table 2).

There were highly statistically significant differences between hyperthyroid, hypothyroid patients, and control group as regards spirometric parameters: $\mathrm{VC} \%$ predicted $(94.15 \pm 4.31,76.90 \pm 7.46$ versus $102.65 \pm 7.63$, respectively), $\mathrm{FVC} \%$ predicted $(90.95 \pm 4.47,72.45 \pm 7.46$ versus $93.80 \pm 3.56)$, FEV1\% predicted $(81.70 \pm 14.54,72.25 \pm$ 11.65 versus $90.55 \pm 2.95)$, FEV1/FVC $(87.15 \pm 5.74$, $78.77 \pm 5.87$ versus $92.36 \pm 4.85$ ), and FEF25-75\% predicted $(72.30 \pm 12.47,72.00 \pm 8.01$ versus $82.70 \pm 9.54)$ with significant decrease in hypothyroidism than hyperthyroidism than control group with $p$ value $<0.001$ (Table 3).

There were also highly statistically significant differences between hyperthyroid, hypothyroid patients, and the control group as regards hormonal profile: TSH $(0.04 \pm 0.06,25.41 \pm 9.50$ and $2.48 \pm 1.00 \mathrm{uIu} / \mathrm{mg}$, respectively), free T3 $(9.29 \pm 2.48,1.58 \pm 0.79$ and $4.49 \pm$ $0.67 \mathrm{pmol} / \mathrm{l})$, and free T4 $(29.40 \pm 4.57,4.37 \pm 2.46$, and $15.75 \pm 1.76 \mathrm{pmol} / \mathrm{l}$ ) with $p$ value $<0.001$ (Table 3 ).

There was a highly statistically significant decrease in diaphragmatic excursion in hypothyroid patients than hyperthyroid patients and a highly statistically significant decrease in patients group than control group as right tidal breathing $(1.61 \pm 0.34,1.42 \pm$ 0.29 versus $2.17 \pm 0.27 \mathrm{~cm}$, respectively), right deep breathing $(5.63 \pm 0.50,5.07 \pm 0.72$ versus $6.63 \pm 0.33$

Table 1 Comparison between groups according to demographic data

\begin{tabular}{llllll}
\hline Demographic data & Hyperthyroidism $(\boldsymbol{n}=\mathbf{4 0})$ & Hypothyroidism $(\boldsymbol{n}=\mathbf{4 0})$ & Control $(\boldsymbol{n}=\mathbf{4 0})$ & $\boldsymbol{F} / \boldsymbol{X}^{\mathbf{2 a}}$ & $\boldsymbol{p}$ value \\
\hline Age (years) & Mean \pm SD & $40.25 \pm 9.98$ & $40.70 \pm 8.87$ & $42.30 \pm 8.95$ & 0.305 \\
& Range & $25-61$ & $29-60$ & $26-55$ & 0.566 \\
Sex & Female & $30(75 \%)$ & $24(60 \%)$ & $28(70 \%)$ & 1.434 \\
& Male & $10(25 \%)$ & $16(40 \%)$ & $12(30 \%)$ & 0.431 \\
BMI $\left(\mathbf{k g} / \mathbf{m}^{\mathbf{2}}\right)$ & Mean \pm SD & $25.68 \pm 2.55$ & $27.53 \pm 2.34$ & $26.04 \pm 3.40$ & 1.775 \\
& Range & $18-28$ & $23.3-30.9$ & $18-30.9$ & 0.193 \\
\end{tabular}

$F$ one-way analysis of variance, $B M I$ body mass index

${ }^{a} X^{2}$ chi-square test

$p$ value $>0.05 \mathrm{NS}$ 
Table 2 Comparison between groups according to upper and lower respiratory symptoms

\begin{tabular}{|c|c|c|c|c|}
\hline Symptoms & Hyperthyroidism $(n=40)$ & Hypothyroidism $(n=40)$ & $x^{2}$ & $p$ value \\
\hline Hoarseness of voice & $14(35.0 \%)$ & $24(60.0 \%)$ & 1.883 & 0.178 \\
\hline Rhinitis & $0(0.0 \%)$ & $2(5.0 \%)$ & 0.040 & 0.741 \\
\hline Dysphagia & $18(45.0 \%)$ & $20(50.0 \%)$ & 0.040 & 0.741 \\
\hline Cough & $8(20.0 \%)$ & $12(30.0 \%)$ & 0.156 & 0.622 \\
\hline Dyspnea & $22(55.0 \%)$ & $22(55.0 \%)$ & 0.000 & 1.000 \\
\hline Wheeze & $0(0.0 \%)$ & $12(30.0 \%)$ & 5.756 & $0.023^{*}$ \\
\hline \multicolumn{5}{|c|}{ Duration of disease (months) } \\
\hline Mean \pm SD & $16.50 \pm 10.56$ & $21.30 \pm 10.15$ & $t=1.805$ & 0.274 \\
\hline Range & $6-39$ & $5-43$ & & \\
\hline
\end{tabular}

$x^{2}$ chi-square test

$p$ value $>0.05 \mathrm{NS}$

${ }^{*} p$ value $<0.05 \mathrm{~S}$

$\mathrm{cm})$, right sniff $(2.67 \pm 0.27,2.15 \pm 0.26$ versus 2.89 $\pm 0.19 \mathrm{~cm})$, left tidal breathing $(1.42 \pm 0.32,1.30 \pm$ 0.30 versus $2.18 \pm 0.31 \mathrm{~cm})$, left deep breathing $(5.41$ $\pm 0.55,4.78 \pm 0.66$ versus $6.41 \pm 0.41 \mathrm{~cm})$, and left sniff $(2.48 \pm 0.23,2.01 \pm 0.31$ versus $2.69 \pm 0.23 \mathrm{~cm})$, $p$ value $<0.001$ (Table 3, Fig. 3).
There was statistically significant decrease in diaphragmatic right end tidal inspiration thickness in hypothyroid patients than control group $(2.69 \pm 0.31$ mm versus $2.89 \pm 0.14 \mathrm{~mm}$ ), $p$ value 0.021 (Table 3 ).

Among hyperthyroid patients, this study revealed negative significant correlations between right tidal

Table 3 Comparison between groups according to pulmonary functions tests, hormonal profile, diaphragmatic excursion, and diaphragmatic thickness

\begin{tabular}{|c|c|c|c|c|c|}
\hline & Hyperthyroidism $(n=40)$ & Hypothyroidism $(n=40)$ & Control $(n=40)$ & ANOVA & $p$ value \\
\hline \multicolumn{6}{|c|}{ Pulmonary function test } \\
\hline VC \% & $94.15 \pm 4.31$ & $76.90 \pm 7.46 a$ & $102.65 \pm 7.63 a b$ & 65.496 & $<0.001^{* *}$ \\
\hline FVC\% & $90.95 \pm 4.47$ & $72.45 \pm 7.46 a$ & $93.80 \pm 3.56 b$ & 76.721 & $<0.001^{* *}$ \\
\hline FEV1\% & $81.70 \pm 14.54$ & $72.25 \pm 11.65 a$ & $90.55 \pm 2.95 \mathrm{ab}$ & 11.869 & $<0.001^{* *}$ \\
\hline FEVI/FVC & $87.15 \pm 5.74$ & $78.77 \pm 5.87 a$ & $92.36 \pm 4.85 \mathrm{ab}$ & 26.074 & $<0.001^{* *}$ \\
\hline FEF $25-75 \%$ & $72.30 \pm 12.47$ & $72.00 \pm 8.01$ & $82.70 \pm 9.54 a b$ & 6.023 & $<0.001^{* *}$ \\
\hline \multicolumn{6}{|l|}{ Hormonal profile } \\
\hline TSH ulU/mg & $0.04 \pm 0.06$ & $25.41 \pm 9.50 \mathrm{a}$ & $2.48 \pm 1.00 \mathrm{ab}$ & 108.271 & $<0.001^{* *}$ \\
\hline Free T3 & $9.29 \pm 2.48$ & $1.58 \pm 0.79 a$ & $4.49 \pm 0.67 a b$ & 105.970 & $<0.001^{* *}$ \\
\hline Free T4 pmol/l & $29.40 \pm 4.57$ & $4.37 \pm 2.46 a$ & $15.75 \pm 1.76 a b$ & 263.809 & $<0.001^{* *}$ \\
\hline \multicolumn{6}{|c|}{ Diaphragmatic Excursion } \\
\hline Rt tidal & $1.61 \pm 0.34$ & $1.42 \pm 0.29 a$ & $2.17 \pm 0.27 a b$ & 28.321 & $<0.001^{* *}$ \\
\hline Rt deep & $5.63 \pm 0.50$ & $5.07 \pm 0.72 a$ & $6.63 \pm 0.33 a b$ & 35.937 & $<0.001^{* *}$ \\
\hline Rt sniff & $2.67 \pm 0.27$ & $2.15 \pm 0.26 a$ & $2.89 \pm 0.19 a b$ & 41.277 & $<0.001^{* *}$ \\
\hline Lt tidal & $1.42 \pm 0.32$ & $1.30 \pm 0.30 \mathrm{a}$ & $2.18 \pm 0.31 a b$ & 39.774 & $<0.001^{* *}$ \\
\hline Lt deep & $5.41 \pm 0.55$ & $4.78 \pm 0.66 a$ & $6.41 \pm 0.41 a b$ & 37.722 & $<0.001^{* *}$ \\
\hline Lt sniff & $2.48 \pm 0.23$ & $2.01 \pm 0.31 a$ & $2.69 \pm 0.23 a b$ & 29.825 & $<0.001^{* *}$ \\
\hline \multicolumn{6}{|c|}{ Diaphragmatic thickness } \\
\hline Rt end tidal insp & $2.83 \pm 0.20$ & $2.69 \pm 0.31$ & $2.89 \pm 0.14 b$ & 4.472 & $0.021^{*}$ \\
\hline Rt end tidal exp & $1.69 \pm 0.27$ & $1.81 \pm 0.19$ & $1.67 \pm 0.22$ & 1.557 & 0.107 \\
\hline
\end{tabular}

$F$ one-way analysis of variance

${ }^{* *} p$ value $<0.001 \mathrm{HS}$

Post hoc: a, significant difference with hyperthyroidism; b, significant difference with hypothyroidism

$B M I$ body mass index, VC vital capacity, FVC forced vital capacity, FEV 1 forced expiratory volume in 1 st second, FEF $25-75 \%$ forced expiratory flow rate $25-75 \%, R$ right, $L t$ left, $T S H$ thyroid stimulating hormone, $T 3$ free triiodothyronine, and T4 free thyroxin 


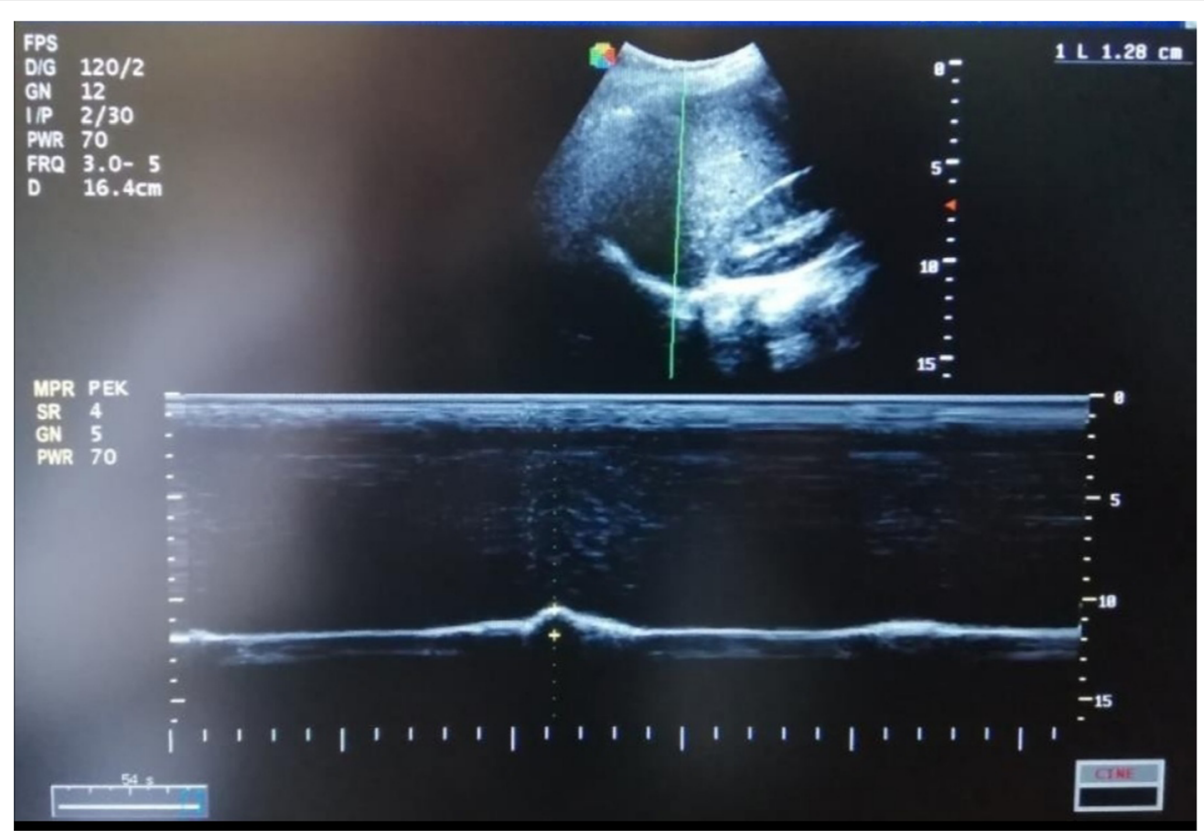

Fig. 3 Ultrasound measurement of diaphragmatic right tidal breathing

diaphragmatic breathing, right sniff, left tidal diaphragmatic breathing, left deep breathing, and duration of diseases. Also, there are negative significant correlations between diaphragmatic right end tidal inspiration and expiration thickness with age. There were positive significant correlations between left tidal diaphragmatic breathing and FEV1/FVC and FEF25-75\% predicted (Table 4).

Among hypothyroid patients, this study revealed negative significant correlations between right tidal diaphragmatic breathing, right deep breathing, left deep breathing, and duration of the disease. There were positive significant correlations between left deep diaphragmatic breathing with $\mathrm{VC} \%$ predicted and left sniff with FEF25-75\% predicted (Table 5).

Multivariant logistic linear regression for predicting factors affecting diaphragmatic excursion in patients group showed that wheeze presence, $\mathrm{FVC} \%$ predicted, FEV1\% predicted, and TSH are independent predicting factors (Table 6).

\section{Discussion}

The present study is one of few studies that investigated the efficiency of diaphragmatic contractility by transthoracic ultrasound in both hypothyroid and hyperthyroid patients in comparison with healthy subjects. This study revealed that there was significant decrease in diaphragmatic movement in patients with thyroid disorders than control. This result is coincident with Goswami et al. [2] who studied 27 patients (19 females and 8 males) with active Graves' disease to assess the clinical severity of dyspnea and the anatomical aspects (thickness and excursion) of the diaphragm at the disease presentation. They revealed that patients with active Graves' disease have significant functional weakness of diaphragm muscle and that this weakness was marked during maximal respiratory maneuver, indicating a diminished diaphragmatic reserve which may cause the dyspnea on exertion among patients with thyrotoxicosis [2].

Also, this study revealed decrease in diaphragmatic end tidal inspiration thickness in hypothyroid group and this result is accepted as in normal individuals. Muscle fibers shorten with contraction and cause muscle thickening while in hypothyroidism, contraction is affected. Increase in diaphragmatic thickness during inspiration has been used as an indirect measurement of muscle fiber contraction [10]. This result can be explained that thyroid hormones have a significant effect on cellular metabolism, and their deficiency leads to disturbance of the normal functioning of the cell. Thyroxine (T4) deficiency leads to a decreased mitochondrial oxidative capacity, abnormal glycogenolysis, and an insulin-resistant state of the cell. This causes selective atrophy of type 2 muscle fibers (fast-twitching type) due to dependency on glycolysis for energy leading to the slowing of muscle contraction seen clinically in patients with hypothyroidism [11]. There is also a decrease in muscle carnitine in thyroid dysfunction patients leading to myopathic symptoms. The muscle affection in hypothyroidism is caused by transforming in muscle fibers from fast-twitching type 2 to slow-twitching type 1 fibers, deposition of glycosaminoglycans, weak 
Table 4 Correlation between diaphragmatic excursion and diaphragmatic thickness with demographic data, duration of disease, and pulmonary function test in hyperthyroidism group

\begin{tabular}{llllllllll}
\hline Hyperthyroidism & & Rt tidal & Rt deep & Rt sniff & Lt tidal & Lt deep & Lt sniff & Rt tidal insp & Rt tidal Exp \\
\hline Age (years) & $r$ & 0.247 & 0.028 & 0.364 & 0.335 & 0.010 & 0.338 & -0.503 & -0.451 \\
& $p$ value & 0.222 & 0.812 & 0.072 & 0.099 & 0.872 & 0.095 & $0.014^{*}$ & $0.025^{*}$ \\
BMI $\left(\mathrm{kg} / \mathrm{m}^{2}\right)$ & $r$ & -0.177 & 0.305 & 0.001 & -0.045 & 0.339 & -0.026 & 0.087 & -0.141 \\
& $p$ value & 0.371 & 0.133 & 0.903 & 0.758 & 0.094 & 0.819 & 0.622 & 0.462 \\
Duration of disease (months) & $r$ & -0.498 & -0.295 & -0.358 & -0.532 & -0.362 & 0.342 & -0.122 & -0.007 \\
& $p$ value & $0.013^{*}$ & 0.146 & $0.042^{*}$ & $0.008^{*}$ & $0.036^{*}$ & 0.092 & 0.517 & 0.882 \\
VC\% & $r$ & 0.363 & 0.057 & 0.214 & 0.055 & 0.047 & 0.156 & 0.103 & 0.359 \\
& $p$ value & 0.116 & 0.811 & 0.365 & 0.818 & 0.845 & 0.513 & 0.666 & 0.120 \\
FVC\% & $r$ & 0.330 & 0.119 & 0.188 & 0.019 & 0.082 & 0.140 & 0.164 & 0.396 \\
FEV1\% & $p$ value & 0.156 & 0.618 & 0.427 & 0.937 & 0.731 & 0.556 & 0.489 & 0.083 \\
& $r$ & -0.013 & 0.090 & 0.038 & 0.089 & 0.129 & -0.060 & 0.017 & -0.166 \\
FEVI/FVC & $p$ value & 0.958 & 0.704 & 0.873 & 0.707 & 0.587 & 0.803 & 0.942 & 0.484 \\
& $r$ & 0.254 & -0.030 & 0.299 & 0.427 & -0.127 & 0.278 & 0.233 & 0.252 \\
FEF25-75\% & $p$ value & 0.280 & 0.899 & 0.201 & $0.036^{*}$ & 0.595 & 0.235 & 0.322 & 0.284 \\
& $r$ & 0.286 & -0.299 & 0.242 & 0.439 & -0.321 & 0.248 & 0.050 & 0.161 \\
\hline Pealson & $p$ value & 0.222 & 0.201 & 0.303 & $0.045^{*}$ & 0.167 & 0.291 & 0.833 & 0.498 \\
\hline
\end{tabular}

$r$ Pearson correlation coefficient

$p$ value $>0.05 \mathrm{NS}$

${ }^{*} p$ value $<0.05 \mathrm{~S}$

${ }^{*} p$ value $<0.001 \mathrm{HS}$

$B M I$ body mass index, VC vital capacity, FVC forced vital capacity, FEV forced expiratory volume in 1 st second, FEF25-75\% forced expiratory flow rate $25-75 \%$

Table 5 Correlation between diaphragmatic excursion and diaphragmatic thickness with demographic data, duration of disease, and pulmonary functions test in hypothyroidism group

\begin{tabular}{llllllllll}
\hline Hypothyroidism & & Rt tidal & Rt deep & Rt sniff & Lt tidal & Lt deep & Lt sniff & Rt tidal insp & Rt tidal Exp \\
\hline Age (years) & $r$ & 0.142 & -0.002 & 0.054 & 0.367 & -0.154 & 0.261 & 0.066 & 0.013 \\
& $p$ value & 0.587 & 0.932 & 0.861 & 0.132 & 0.555 & 0.297 & 0.824 & 0.443 \\
BMI (kg/m2) & $r$ & 0.205 & 0.174 & 0.168 & 0.167 & 0.191 & -0.176 & 0.178 & 0.098 \\
& $p$ value & 0.422 & 0.500 & 0.516 & 0.519 & 0.454 & 0.495 & 0.491 & 0.721 \\
Duration of disease (months) & $r$ & -0.450 & -0.858 & -0.115 & -0.254 & -0.823 & 0.168 & -0.066 & -0.054 \\
& $p$ value & $0.046^{*}$ & $<0.001^{* *}$ & 0.668 & 0.311 & $<0.001^{* *}$ & 0.516 & 0.823 & 0.861 \\
VC\% & $r$ & 0.299 & 0.280 & 0.357 & 0.213 & 0.429 & -0.043 & 0.125 & -0.365 \\
& $p$ value & 0.201 & 0.232 & 0.122 & 0.366 & $0.026^{*}$ & 0.857 & 0.599 & 0.114 \\
FVC\% & $r$ & 0.278 & 0.198 & 0.343 & 0.176 & 0.334 & -0.072 & 0.170 & -0.276 \\
FEV1\% & $p$ value & 0.236 & 0.402 & 0.139 & 0.459 & 0.150 & 0.764 & 0.473 & 0.240 \\
& $r$ & 0.241 & 0.160 & 0.359 & 0.120 & 0.338 & 0.086 & 0.052 & -0.396 \\
FEVI/FVC & $p$ value & 0.305 & 0.501 & 0.120 & 0.614 & 0.145 & 0.720 & 0.826 & 0.084 \\
& $r$ & -0.153 & -0.118 & 0.137 & -0.022 & 0.035 & 0.059 & 0.345 & 0.107 \\
FEF25-75\% & $p$ value & 0.520 & 0.620 & 0.565 & 0.927 & 0.885 & 0.804 & 0.136 & 0.654 \\
& $r$ & 0.016 & 0.184 & 0.043 & -0.137 & 0.355 & 0.396 & 0.004 & -0.330 \\
\hline
\end{tabular}

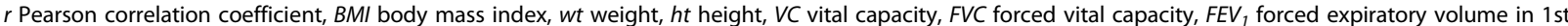
second, FEF25-75\% forced expiratory flow rate $25-75 \%$

$p$ value $>0.05 \mathrm{NS}$

${ }^{*} p$ value $<0.05 S$

${ }^{* *} p$ value $<0.001 \mathrm{HS}$ 
Table 6 Logistic linear regression of the predictive factors for diaphragmatic excursion affection in patients' group

\begin{tabular}{llllll}
\hline Parameters & B & Sig. & $\begin{array}{l}\text { Odds } \\
\text { ratio }\end{array}$ & & 95 C.I. \\
\cline { 5 - 6 } & & & Lower & Upper \\
\hline Wheeze & -1.407 & $0.004^{\mathrm{a}}$ & 2.792 & 1.815 & 5.501 \\
VC\% & -0.843 & 0.301 & 2.055 & 1.337 & 4.050 \\
FVC\% & -1.399 & $0.049^{\mathrm{a}}$ & 2.223 & 0.710 & 3.282 \\
FEV1\% & -2.505 & $0.028^{\mathrm{a}}$ & 2.396 & 1.557 & 4.720 \\
FEVI/FVC & -0.304 & 0.919 & 1.236 & 0.694 & 3.234 \\
TSH ulu/mg & 1.083 & $0.016^{\mathrm{a}}$ & 0.920 & 0.837 & 2.538 \\
Free T3 & -0.325 & 0.835 & 1.288 & 0.837 & 2.538 \\
Free T4 pmol/I & -0.622 & 0.468 & 1.365 & 0.887 & 2.691 \\
\hline
\end{tabular}

${ }^{\mathrm{a} S i g n i f i c a n t ~ f i g u r e s}$

contractility of actin-myosin units, low myosin ATPase activity, and low ATP turnover in muscle. It has been noticed that the degree of muscle weakness does not often correlate with the severity of thyroid hormone deficiency and this recommends that for associated impaired muscle function, structural muscle injury might have a role in the pathogenesis of muscle weakness [12].

The present study revealed positive significant correlation between right diaphragmatic excursion and FEV1/ FVC and FEF25-75\% in hyperthyroid patients and positive significant correlation between left deep diaphragmatic breathing with $\mathrm{VC} \%$ and left sniff with FEF25-75\% in hypothyroid patients which is coincident with the results of Adel et al. [13] that studied 107 healthy persons who came for routine preoperative lung function assessment or normal volunteers. Spirometry and diaphragmatic assessment by ultrasound for excursion and thickness were done for all persons; there were highly significant statistical increase in right diaphragmatic excursion and both right and left diaphragmatic thickness when FEV1 increases. A significant increase in left excursion and diaphragmatic thickness fraction (DTF) was also noticed with increased FEV1. However, there was significant decrease in DTF with increase in FVC\% [13]. Our results also are in concordance with Youssuf et al. [14] who studied the role of transthoracic ultrasound in evaluating patients with chronic obstructive pulmonary disease on 60 male participants and found a statistically significant positive correlation between FEV1 and diaphragmatic excursion, but that study was on the right side only [14]. Similar results were observed by Eman et al. [15] who assessed diaphragmatic thickness, excursion, and fatigue in 45 asthmatic children (23 boys and 22 girls) with various clinical and functional grading at Ain Shams University Hospital, Cairo, and found that there was a positive correlation between FEV1 and diaphragmatic excursion and thickness [15].
This study revealed a high statistically significant difference between hyperthyroid, hypothyroid patients, and control group as regards spirometric parameters. Spirometric parameters were reduced in hypothyroidism in comparison to hyperthyroidism and controls which is coincident with Eman et al. [15] who studied 90 participants (30 patients with hyperthyroidism, 30 patients with hypothyroidism, and the remaining 30 were normal healthy volunteers as control) and found that all spirometric functional parameters were decreased (whether or not significant) among patients with hypothyroidism and hyperthyroidism compared with normal euthyroid controls and that more statistically significant respiratory functional impairment was noticed among patients with hypothyroidism than among those with hyperthyroidism [16].

The present study revealed negative correlation between diaphragmatic excursion and duration of diseases in patients' group and negative correlation between diaphragmatic thickness and age in hyperthyroid group. To the best of our knowledge, these correlations were not investigated before.

The present study revealed associations between upper and lower respiratory symptoms in the form of hoarseness of voice, rhinitis, dyspnea, cough, and wheezes with thyroid disorders being more prevalent in hypothyroidism. These results agreed with Eman et al. [15] who found that respiratory symptoms were more frequent in hypothyroid than in hyperthyroid patients, especially cough, sputum production, and chest wheezes [16], and also with Basal et al. [4] who concluded that thyroid hormone receptors are present in nasal mucosa and that edema, inflammation, and vascular proliferation occur in nasal mucosa due to hypothyroidism [4]. Also, our results agreed with Goswami et al. who found that $88.8 \%$ of patients with active Graves' disease had dyspnea [2]. The most frequent symptoms of rhinitis related to hypothyroidism are nasal obstruction and rhinorrhea, which are caused by an increase in submucosal connective tissue and hypertrophy of mucous glands. The pathophysiological mechanism of hormonal rhinitis associated with hypothyroidism has not been clearly identified [17].

Multivariant logistic linear regression of predicting factors affecting diaphragmatic excursion in hyperthyroidism versus hypothyroidism showed that presence of wheeze, FVC\%, FEV1\%, and serum TSH have a significant predicting value.

\section{Conclusion}

Diaphragmatic excursion and thickness are affected in hypothyroidism compared to hyperthyroidism and control groups. There is significant negative correlation between diaphragmatic excursion and duration of disease and positively correlated with VC, FEV1/FVC, and 
FEF25-75 among patients' group, and respiratory symptoms were more frequent in hypothyroid in patients' group.

\section{Limitation of study}

There is a need to conduct this study on a large number of patients and follow these patients after control of their hormonal profile to study the reversibility of diaphragmatic contractility affection. Further studies are recommended to find an easy, inexpensive biomarkers or tool to identify the diaphragmatic affection in thyroid patients and to guide therapeutic choices.

\section{Abbreviations}

BMI: Body mass index; VC: Vital capacity; FVC: Forced vital capacity; FEV1: Forced expiratory volume in 1st second; FEF25-75\%: Forced expiratory flow rate 25-75\%; Rt: Right; Lt: Left; DTF: Diaphragmatic thickness fraction; TSH: Thyroid stimulating hormone; T3: Free triiodothyronine; T4: Free thyroxin

\section{Acknowledgements}

Not applicable

\section{Authors' contributions}

HHE conceived of the presented idea, carried out spirometry and diaphragmatic ultrasound, and wrote the manuscript with support of $1 \mathrm{HA}$ FME developed the theory and performed the computations. SAN verified the analytical methods. All authors discussed the results and contributed to the final manuscript. The author(s) read and approved the final manuscript.

\section{Funding}

Nil

\section{Availability of data and materials}

All data generated or analyzed during this study are included in this published article (and its supplementary information files).

\section{Ethics approval and consent to participate}

Written informed consent was signed by all recruited participants. This study was approved by the institutional review board of Faculty of Medicine for Girls, Al-Azhar University, Cairo branch (No. 202002163) and was obliged to the standards of the Declaration of Helsinki.

\section{Consent for publication}

Not applicable

\section{Competing interests}

There is no competing interest to be declared.

\section{Author details}

'Department of Chest Diseases, Faculty of Medicine for Girls in Cairo, Al-Azhar University, 11517 Al-Abbaseya, Cairo, Egypt. ²Department of Endocrinology, Faculty of Medicine for Girls in Cairo, Al-Azhar University, Cairo, Egypt. ${ }^{3}$ Department of Ear, Nose and Throat, Faculty of Medicine for Girls in Cairo, Al-Azhar University, Cairo, Egypt. ${ }^{4}$ Department of Internal Medicine, Faculty of Medicine for Girls in Cairo, Al-Azhar University, Cairo, Egypt.

Received: 3 July 2020 Accepted: 17 September 2020

Published online: 25 September 2020

\section{References}

1. Sadek SH, Khalifa WA, Azoz AM (2017) Pulmonary consequences of hypothyroidism. Ann Thorac Med 12(3):204-208

2. Goswami R, Guleria R, Gupta AK, Gupta N, Marwaha RK, Pande JN et a (2002) Prevalence of diaphragmatic muscle weakness and dyspnoea in Graves' disease and their reversibility with carbimazole therapy. Eur J Endocrinol 147:299-303
3. Zambon M, Greco M, Bocchino S, Cabrini L, Beccaria PF, Zangrillo A (2017) Assessment of diaphragmatic dysfunction in the critically ill patient with ultrasound: a systematic review. Intensive Care Med 43(1):29-38

4. Başal Y, Günel C, Özkavruk Eliyatkın N, Cesur G, Eryılmaz A (2018) The effect of experimental hypothyroidism on nasal mucosa. Tr-ENT. 28(1):21-25

5. Sin DD, Miravitlles M, Mannino DM, Soriano JB, Price D, Celli BR et al (2016) What is asthma-COPD overlap syndrome? Towards a consensus definition from a round table discussion. Eur Respir J 48:664-673

6. Pasero D, Koeltz A, Placido R, Fontes Lima M, Haun O, Rienzo M et al (2015) Improving ultrasonic measurement of diaphragmatic excursion after cardiac surgery using the anatomical M-mode: a randomized crossover study. Intensive Care Med 41:650-656

7. Testa A, Soldati G, Giannuzzi R, Berardi S, Portale G, Gentiloni Silveri N (2011) Ultrasound M-mode assessment of diaphragmatic kinetics by anterior transverse scanning in healthy subjects. Ultrasound Med Biol 37(1):44-52

8. Matamis D, Soilemezi E, Tsagourias M, Akoumianaki E, Dimassi S, Boroli F et al (2013) Sonographic evaluation of the diaphragm in critically ill patients. Technique and clinical applications. Intensive Care Med 39:801-810

9. Umbrello M, Formenti P, Longhi D, Galimberti A, Piva I, Pezzi A et al (2015) Diaphragm ultrasound as indicator of respiratory effort in critically ill patients undergoing assisted mechanical ventilation: a pilot clinical study. Crit Care 19(1):161

10. Gottesman E, McCool FD (1997) Ultrasound evaluation of the paralyzed diaphragm. Am J Respir Crit Care Med 155:1570-1574

11. Sindoni A, Rodolico C, Pappalardo MA, Portaro S, Benvenga S (2016) Hypothyroid myopathy: a peculiar clinical presentation of thyroid failure. Review of the literature. Rev Endocr Metab Disord 17(4):499-519

12. Vignesh G, Balachandran K, Kamalanathan S, Hamide A (2013) Myoedema: a clinical pointer to hypothyroid myopathy. Indian J Endocrinol Metab 17(2):352

13. Adel SM, Hieba EG, Hossam SH (2019) Assessment of diaphragmatic mobility by chest ultrasound in relation to BMl and spirometric parameters. Egypt J Bronchol 13(2):232-243

14. Youssuf HA, Abdelnabi EA, Abd El Hafeez AM, Fathallah WF, Ismail JH (2016) Role of transthoracic ultrasound in evaluating patients with chronic obstructive pulmonary disease. Egypt I Bronchol 10:274-282

15. Eman MF, Mahitab M, Safaa KM, El-Kahky AM, Al Azziz MA. Ultrasonography assessment of diaphragm in asthmatic children and effects of diaphragm strengthening exercise on angiogenin level and pulmonary functions. Int J Pul Res Sci. 2017; 1(5): 555574

16. Ali ER (2016) Assessment of functional lung impairment in patients with thyroid disorders. Egypt J Bronchol 10(3):337-347

17. Salib RJ, Harries PG, Nair SB, Howarth PH (2008) Mechanisms and mediators of nasal symptoms in non-allergic rhinitis. Clin Exp Allergy 38:393-404

\section{Publisher's Note}

Springer Nature remains neutral with regard to jurisdictional claims in published maps and institutional affiliations.

\section{Submit your manuscript to a SpringerOpen ${ }^{\circ}$ journal and benefit from:}

- Convenient online submission

- Rigorous peer review

- Open access: articles freely available online

High visibility within the field

- Retaining the copyright to your article

Submit your next manuscript at $\boldsymbol{\nabla}$ springeropen.com 